\title{
LEIBNIZ AND RELATIONALITY ${ }^{*}$
}

\author{
M. GLOUBERMAN \\ University of Negev
}

1. Bertrand Russell's interpretation of Leibniz's theory of basic propositional form, which reads the texts as saying that '[e]very proposition is ultimately reducible to one which attributes a predicate to a subject', ${ }^{2}$ is the received view on the topic. An indication of the extent to which this interpretation is entrenched is supplied by the sharp reaction of an influential commentator, Jonathan Bennett, to the closely reasoned dissenting opinion of Hide Ishiguro. '[Ishiguro's view] is interesting and considerable, but I am entirely unconvinced by it'."

It is a curious feature of the dispute that the very texts normally cited as evidence for the standard reading are brought by Ishiguro in testimony against it. This suggests, what I will try to bear out, that neither construal is based on a proper understanding of Leibniz's claims. While there

1 References to classical sources are built into the text, finest section locations in original editions being given. Numbers after a slash give pagination in translated editions. The following translations are used. Leibniz: New Essays Concerming Human Understanding is translated by A. G. Langley (La Salle, Illinois, 1916). All other quotations are from Leibniz Philosophical Papers and Letcers, translated and edited by L. E. Loemker (D. Reidel: Dordrecht-Holland, 1969). Kant: Critique of Pure Reason, cited in standard A/B form, is translated by N. K. Smith (Macmillan: London, 1964). Logic is translated by R. Hartman and W. Schwarz (Bobbs-Merrill: Indianapolis and New York, 1974). Spinoza: Passages are cited from Volume II, Works of Spinoza, tranglated by R. H. M. Elwes (Dover: New York, 1955). Wittgenstein: Tractatus Logico-Philosophicus is translated by D. F. Pears and B. F. McGuinness (Routledge \& Kegan Paul: London, 1963).

2 A Critical Exposition of the Philosophy of Leibniz (George Allen \& Un. win: London, 1971), p. 9.

3 In Leibniz's Philosophy of Logic and Language (Duckworth: London, 1972).

4 Kant's Dialectic (Cambridge U. P.: London, 1974), p. 47. 
is a sense in which Leibniz requires relationality to be eliminated from standard factual propositions as a condition of their metaphysical acceptability, 'relationality' does not mean here what both Bennett and Ishiguro take it to mean. Once the lie of the Leibnizean land is properly mapped, the issue normally debated under the rubric of 'Leibniz's theory of relationality' emerges in an entirely different light.

Because the textual evidence on which I rely is wellknown, I will proceed dialicetically rather than in strict exegetical fashion, taking the recent interpretations as my primary data, and letting the discussion develop from there.

2. In support of his standard interpretation of Leibniz's doctrine of relationality, Bennett compares it with another Leibnizean doctrine, over which there is no dispute, viz. the doctrine of monadic ${ }^{3}$ indivisibility. Let us examine the comparison.

In the Monadology, Leibniz argues as follows. Spatial occupants like chairs and tables are composites. As there are composites, there must be unities of which they are composed. But all spatial occupants, no matters what their dimensions, are divisible, so no true unities can be found among them. Therefore, the true substantial unities are nonspatial.

The significant feature of this argument, for present purposes, is the move made from one realm to an entirely different and putatively more basic one. Leibniz would scoff at an experimental or scientific programme to isolate basic substantial unities in the spatial realm. The whole point of the argument is that this realm must be superseded in its entirety if the foundational level is to be reached.

According to Bennett, precisely the same sort of move must be made in order to reach basic propositional forms from the starting point of standard factual discourse: 'all

5 To avoid confusion, “monadic' is used exclusively to mean 'of monads'. The term is not employed in the logical sense of 'non-relational' or 'l-place'. 
such replacements [of standard by basic forms] operate across a boundary which is ... mysterious, with ultimate reality on one side of it and the whole ... world [as normally conceived] on the other':

It is clear why Bennett believes that the comparison tells against Ishiguro's reading. That reading gets its prima facie appeal from the fact that we cannot see how many standard $n>1-p l a c e$ propositions can conceivably be replaced by (sets of) 1-place ones. So the intuitive plausibility of Leibnizeanism increases if we deny its commitment to replacement. But -Bennett would insist - to argue in this way is simply to ignore the frankly metaphysical character of Leibniz's thought: it is to ignore how Leibniz, precisely as in arguing for monadic indivisibility, doesn't restrict himself to standard resources in order to carry out the task. Considerations of intuitive plausibility are completely out of place here. To argue as Ishiguro does is akin, mutatis mutandis, to arguing, in a clearly misguided fashion, that because spatial items are divisible without end, their basic constituents must in turn be divisible.

Bennett's comparison is critically apt. By underlining the parallels between the argumentation for the two doctrines, one can clarify Leibniz's view of relationality. But while Bennett succeeds in showing, in this way, that what Ishiguro treats largely as a technical problem has a metaphysical depth which she ignores, it is more significant that Bennett himself is not consistent in describing how the two doctrines are parallel. By trying to reinstate parallelism, we begin to see that Bennett's conclusions about Leibniz's views of relationality are not the right ones.

3. There are two ways in which Bennett is untrue to his own comparison. First, because the ideas of composition and divisibility naturally go hand in hand with those of indivisibility and non-compositeness, it is easy to see how one who,

B Bennett, Kant's Dialectic, p. 48. 
like Leibniz, holds that spatial composition is indefinite, thereby has a perfectly natural motive for transcending the spatial realm in search of genuine units of composition. (I do not say that this is a logically or metaphysically compelling motive, only that it is prima facie persuasive.) But there is no correspondingly obvious way in which the idea of relationality, as understood by Bennett, goes hand in hand with that of non-relationality. Given a relation, it is true that relata, i.e. related items, are presupposed: one could argue in an intuitively natural way from a relation to relata. But this is quite different from arguing, as Leibniz is presented by Bennett as arguing, from $n>1$-place relational propositions to 1-place predicative propositions.

This is one way in which Bennett's comparison is unsatisfactory. It fails to find a motive for transcending relational propositions parallel to the clear motive for transcending spatial items.

The second flaw is more serious. The doctrine of monadic indivisibility is the doctrine that there are non-spatial items, monads, which cannot conceivably be divided in the way that spatial occupants like tables and chairs can be divided. Even an advocate of physical atoms wouldn't dream or arguing that non-spatial items like monads (which Leibniz compares with souls) are indivisible in the very sense in which atoms are, in his view, indivisible.

So here the line between the normal phenomenal realm and the metaphysically basic realm of monads is a line between items all of which are, according to Leibniz, divisible, and items whose divisibility in this sense cannot intelligibly be conceived. If there is a comparison between this doctrine and the doctrine that relations must be reduced or replaced, we expect that all non-basic propositions of the standard factual realm will be described as relational, and that this kind of relationality will be unintelligible in the basic realm.

Bennett doesn't draw the line in this way. He proceeds entirely unconcerned by the fact that, on his construal of 'relationality', non-relational propositions are available in 
the non-basic realm. By the terms of his own comparison, this must be a blunder. For suppose we take the same attitude to divisibility. We would thus find ourselves saying that indivisible items might well be available in the phenomenal realm, i.e. that their unavailability cannot be determined philosophically. But, as we know, it is the very nerve of Leibniz's argument for superseding the spatial realm that all spatial items are divisible.

Either Bennett's comparison is mistaken (in which case his criticism of Ishiguro, based on the comparison, loses its force) or else he has not properly grasped what Leibniz's position on relationality is. To sustain parallelism, i.e. to sustain the comparison, we require an interpretation of the idea of relationality which satisfies the following two conditions. By parity with the case of divisibility, (1) relationality will be restricted to the phenomenal side of the boundary, and will affect all propositions of the phenomenal realm, and (2) that a phenomenal proposition is relational constitutes an intelligible reason for seeking to replace it by propositions which are free of this kind of relationality.

4. A curious volte face seems to have taken place. In light of condition (1), it seems that Bennett ought, by the very terms of his comparison, to be sympathetic towards, rather than to attack, Ishiguro's claims.

Ishiguro argues that many standard factual propositions, which appear to have the form $F(a)$, are really of the form $\mathbf{R}(\mathrm{a}, \mathrm{b}, \ldots)$. Thus, she moves some way towards the thesis that all standard factual propositions are relational.

It is me, however, not Ishiguro, who adumbrates a thesis of pan-relationality. Hers is the more moderate claim that there are great technical difficulties in drawing the line between 1-place and $n>1$-place propositions, not the radical one that there is, in principle, no line to be drawn.

But the thesis of pan-relationality is not my own dialectical creation. Its historical reality is confirmed by the texts. 
Consider first Locke's tentative version of a general thesis of relationality:

however absolute and entire [things] seem in themselves, [they] are but retainers to other parts of nature for that which they are most taken not of by us. Their observable qualities, actions, and powers are owing to something without them; and there is not so complete and perfect a part that we know of nature which does not owe the being it has, and the excellences of it, to its neighbours; and we must not confine our thoughts within the surface of any body, but look a great deal farther, to comprehend perfectly those qualities that are in it (Essay 4.6.11).

This passage can also perhaps he read moderately, along Ishiguro's lines. But Locke's boldness hints of a deeper basis for his view, and the slant of the Essay suggests that it will be epistemological.

Kant puts the issue in sharper perspective, Addressing himself to Leibniz, Kant argues in an unrestricted way for the same result:

I have therefore nothing that is absolutely, but only what is comparatively inward and is itself again composed of outer relations. The absolutely inward [nature] of matter, as is would have to be conceived by pure understanding, is nothing but a phantom (A277; B333).

None of Locke's tentativeness remains here. And we can see the deep epistemological basis for Kant's claim. That our normal distinction between relational and non-relational (= outward and inward) is comparative, not absolute, follows from the fact that ours is not a 'pure understanding'. In order to achieve non-relationality, our normal style of cognition must be superseded. So it is clear that the problem 
of reaching absolute inwardness is a principled, not a tech. nical, one.

Beneath its Kantian exterior, this is a recognisable variant of Leibniz's view. The difference between Kant and Leibniz consists in this, that Kant denies, while Leibniz maintains, that our cognitive resources are equal to the task of transcending (mere) comparative inwardness.

This isn't the place for an exposition of Kant's position on cognition. It is easy enough to recognise, in the domestic phraseology of the critical philosophy, that Kant's disagreement with Leibniz devolves precisely to the relationaliy of standard cognition. For example, a constant Kantian refrain is that we cognise things 'as they appear', not 'as they are (in themselves)'. As the reader will note, 'appear' (tacitly) introduces relationality: to speak of an object as 'appearing' is to speak of it as 'appearing to someone, who therefore stands in a specific relation to it'. And Kant describes conceptual contents as 'sided determinations' (Logic/105). I.e. the contents of Kant's basic vehicles of representation represent the accusatives we cognise in terms of their aspects, and 'aspect', like 'appearance', is a(n implicitly) relational term.

The same theme, with a different moral, is present in Leib. niz. Speaking of phenomenal notions like extension and motion, Leibniz describes them as partly 'imaginary', which he glosses as 'relative to our perceptions' (Discourse on Metaphysics 12). And he contrasts the metaphysically "defective cognition of a person, 'according to the measure of his own point of view' (ibid. 14), with God's metaphysically adequate cognition: '[God] sees the universe not as [people] see it but also entirely differently from all of them' (ibid. ibid.).

Though these remarks are sketchy, it is evident that they can be used to reinstate parallelism between the two Leib. nizean doctrines which Bennett compares. Moreover, we see that there are genuine historical reasons for doing go.

The thesis that standard factual propositions are uniform- 
ly relational reestablishes parity with Leibniz's claim that objects in the phenomenal realm are uniformly divisible. Also, because the relationality here traces to a structural feature of cognition which Leibniz rejects as metaphysically distortive, it supplies an intelligible reason for superseding the standard realm. Thus, requirements (1) and (2) of the preceding section are satisfied.

5. As I said at the start, there is thus a sense in which Leibniz requires relationality to be comprehensively eliminated. But the term 'relationality' here-to be clarified further below-means something different from the homonymous term used by Bennett, by Ishiguro, by commentators generally. Doesn't this make the preceding discussion irrelevant to the debate between them? Let me make three points in reply. (To avoid confusion, I will henceforth put 'relationality*' when using the term as per the thesis adumbrated above, that a certain structural feature of standard cognition must be overcome in the name of metaphysical accuracy.)

First, I claim that Leibniz's doctrine, viz. that relationality* must be eliminated, is not properly understood by commentators, because they construe it as the different claim that relationality must be eliminated. So it is question-begging to say that my discussion is irrelevant to the standard debate.

Consider this characteristic text: "every true predication has some basis in the nature of things' (Discourse on Metaphysics 8). Speaking for the received view, Bennett would interpret this as saying that normal factual propositions are replaceable by 1-place propositions expressing the 'internal' character of (metaphysically basic) things. Ishiguro, opposing this view, will read it as saying that nothing can be merely a subject of a relational claim: any relatum must have some internal character in order to be a possible relatum.

But to construe in either of these ways is to ignore context. Leibniz's contrast is between 'in the nature of things' and 
'relative to our understanding', i.e. 'relative*'. And this has nothing to do with the contrast between 1-place and n> l-place propositions.

It cannot however be maintained with any real plausibility that Leibniz never writes in a way which invites the conventional interpretation of, and hence debate over, relationality. So my second point is that, on the basis of the preceding discussion, we can find grounds for imputing confusion to Leibniz for writing in this way. Again, Bennett's comparison helps out here.

Consider the doctrine of monadic indivisibility. Because monads are not spatial beings, the proposition that they are indivisible is best interpreted as a categorial claim, like the proposition that numbers are not angular. In neither case is the normal ascription of the contradictory predicate true: just as numbers are not non-angular in the way that a (curvilinear) ellipse is, so monads are not indivisible in the way that a spatial occupant might be.

Glancing now at the start of the Monadology, the impression is strong that Leibniz does move from the (categorial) denial that monads are divisible to the truth of the standard predication that monads are indivisible. But 'divisible' as applicable to spatial items is categorially inappropriate to (non-spatial) monads. So this claim is either senseless or merely assumed without argument. It is senseless if it means that monads cannot be cloven by cutting. It is unargued for if it means that there is no sense of 'divisibility' at all in which (non-spatial) monads are divisible. By parity of reasoning, it would be clearly mistaken to argue that because numbers, being non-spatial, are not divisible in the sense that chairs are, therefore numbers are indivisible simpliciter. This is falsified every time we divide 4 by 2 and reach 2.

It would not be hard for Leibniz to make a similar blunder in respect of relationality*. Because he holds that normal factual propositions, including $n>1$-place propositions, i.e. including relational propositions, are infected by relation- 
ality*, it would be easy for him to conclude that because relationality* must be eliminated, basic propositions cannot be relational. But this, in turn, is either senseless or dogmatic. It is senseless if it means that, in the very way in which ' $a$ is to the left of $b$ ' is relational, monadic propositions are non-relational. Being non-spatial, monads can neither be, not fail to be, related in this way. It is dogmatic if it means that there is no appropiate sense of relationality such that monadic propositions can be relational.

The third point takes us slightly farther afield. A misleading feature of many modern discussions of the tradition is that (what is identified as) Leibniz's problem of relationality is presented as unique to him, or at any rate as associated in a particularly close way with him. But the same problem is clearly recognised, among the pre-Kantians, by Descartes, Spinoza, and Hume.

Hume's position is crucial here. His analysis of the causal link as an irrational link between distinct existences is fully in accord, in a negative way, with the positions of the rationalists. In Leibniz's doctrine of pre-established harmony, we find an attempt to ensure that no such irrationality will mar the world's ultimate intelligibility. However, as this shows, the objection is not to relations simpliciter, but to particular kinds of relation, viz. irrational ones. That Leibniz appeals to a metaphysical principle in order to sustain the intelligibility of monadic order implies that the idea of an order among monads makes independent sense.

Consider also how Spinoza, who reads 'irrational' or 'unintelligible' as 'impossible', therefore denies the possibility of Humean causal ties among substances. (The case of Spinoza is complicated here by his confusion of 'causal tie' and 'logical tie'. He thus denies that causally related items are distinct existences. But let us ignore this confusion.) Again, what counts against relations of a certain kind is their unintelligibility from the standpoint of a particular paradigm of explanation. They are not disqualified simply for being relations. 
6. Leibniz's primary motive for demanding that standard forms be superseded is that they are infected by relationality*. I want to examine this motive more closely. This will lead to an explanation of what it means to cross Bennett's 'mysterious boundary'. From a formal viewpoint, the passage is, I think, less mysterious than Bennett would have us believe.

We can begin with Kant's claim that absolute inwardness is a 'phantom' notion. Because 'absolute inwardness' means 'non-relationality*' rather than 'non-relationality', this claim is very badly paraphrased as the claim that factual propositions normally said to be of the form $F(a)$ are really of the relational form $R(a, b, \ldots)$, i.e. that their prima facie non-relationality is misleading. The factor singled out by Kant as responsible for the relationality* of standard forms is a structural feature of nomal cognition, a 'trascendental factor', Kant would say. So it is not representable as just another influence on factual propositions.

According to Kant, a 'pure understanding' would have to be activated in order to grasp an accusative non-relationality*. This duplicates Leibniz's thesis that normal modes of cognition and experience are 'confused', that they represent the world 'phenomenally', rather than as it really is. In effect, Kant's discusive style of cognition, involving the application of concepts to sense-given data, corresponds to what Leibniz regards as 'impure' or 'metaphysically inadequate' cognition.

What is it about a discursive mode of cognition that marks it as 'confused', 'indistinct', 'impure', 'superficial', 'inadequate', 'partial', 'incomplete', etc.? The answer is provided by Kant's blanket claim that 'every concept is an abstract concept' (Logic/105). Concepts - the vehicles of discursive representation - are abstract in content. According to Leibniz -according, in fact, to all pre-Kantians of the Cartesian tradition (with the possible exception of Locke) - abstract cognition is the philosopher's mortal foe. The tireless onslaught on abstractions in pre-Kantian philosophy is obvious 
to a reader even marginally acquainted with the texts, as well as the fact that it is linked with a critique of language (= a discursive style of representation). It is thus perfectly natural that Kant should say that cognition, as he sees it; is in principle unequal to the task of representing things as they are in themselves.

Here is some relevant evidence of Leibniz's membership in the club. While he admits that

abstractions are necessary for the scientific explanation of things (Letter to de Volder/531),

he nevertheless insists that

there is as great a difference between substance and mass as there is between complete things as they are in themselves and incomplete things as we accept them through abstraction (ibid./ibid.),

and he characterises standard, scientific, terms as

incomplete and abstract concepts, which thought supports but which nature does not know in their bare form (ibid./ 529).

By contrast with standard modes of cognition, in his claim that

God's resolution are never abstract and imperfect (LeibnizClarke Controversy 5.66),

Leibniz restates Spinoza's view that

God does not know things through abstraction, or from general definitions (Letter to Blyenbergh/333).

In sum: a style of cognition, like discursive cognition, 
which employs abstract vehicles of representation, is metaphysically inadequate according to Leibniz.

Concentrating on space and spatiality, which are phenomenal, and hence marred by cognitive confusion in Leibniz's view, let us now draw out the more specific implications of this result.

Consider the following Kantian claim:

not only are the drops of rain [i.e. physical objects] mere appearances, but... even their round shape, nay even the space in which they fall, are nothing in themselves, but merely modifications or fundamental forms of our sensible intuition (A46/B63).

That Leibniz's sentiments are similar emerges from the following pair of claims:

Space, time, extension, and motion are not things but wellfounded modes of our consideration (First Truths/270). [M] odes are usually nothing but the relations of a thing to the understanding, or phenomenal capacities (Preface to an Edition of Nizolius/126).

The key fact is the classification of phenomenal features as modes. By exploring this classification, we can achieve a proper explanation of what cognitive abstractness consists in.

7. What is a mode? Modes contrast, as in the second to last passage, with things, i.e. substances. A substance is a self-subsistent entity; a mode is a dependency, depending for its being on something beyond it in a way in which a substance does not depend on anything further. Modes, in short, can be described as abstract or dependent particulars.

To neutralise the effects of a common misunderstanding, let me expand slightly on the claim that modes are particulars.

Consider the colour of an object, as represented in the 
standard claim 'The table is red'. Normally, the object is represented as the designatum of a singular referring expression, and the colour - a modification of the table- is introduced by a general term functioning predicatively. But if, following this normal fact, we classify modes as general things, e.g. properties capable of being instantiated by a number of objects, then the idea of a confusion of a mode and a substance is senseless. Hoy can a general thing be mistaken for a particular?

It would thus make no sense for a classical philosopher to attack modes on the score of their abstractness insofar as these are represented in normal patterns of thought and talk by general terms. Such a one attacks the standard view of the world, of course, on the grounds that its practitioners mistakenly identify non-substances as substances. Consider Spinoza's claim that material particulars are modes: according to Spinoza, 'the table' as operating in 'The table is red' picks out a (Spinozistic) non-substance. But 'the table' is a singular designator, not a general predicate. So while Spinoza might describe as adequate a style of world-representation in which 'table' (or some non-nominal cognate thereof, e.g. 'tabular') functions only in predicate position, that style of cognition would not be one in terms of which he could locate what he regards as the confusion in normal cognition. Accordingly, talk of abstractions or of modes is talk of abstract or modal particulars in the critical portions of classical texts.

The ability of a modal term to appear singularly and in predicate position is not, I might add, in the least problematic, even apart from the metaphysical concerns of the tradition. The content of 'The table is red' is duplicated by 'The red colour belongs to the table', in which the colour is introduced by a singular designator. But to employ the latter form, which is more complex than the normal forms, is needlessly uneconomical. Given that substances are basic individuables, there is no reason to pick out their modifications 
as well by singular terms. Having identified the substance, it is enough to employ a predicate to introduce the modification. However, to repeat, because the classical metaphysicians deny that we normally recognise basic individuals, this implies that mundane patterns of discourse will, in their view, invariably introduce some non-substances by means of singular terms. 'The table', for Spinoza, is a case in point.

To strengthen our grasp of these matters, let me give an example of a case in which it will be agreed that a mode is being misrepresented as a substance.

A murder, standardly, will be classified as a modal particular. If a murder takes place, there must be actors, Jones and Smith say, the one a mafia hit man, the other a stool pigeon. Jones and Smith, by contrast, are standardly classified as concrete particulars. Their integrity as individuals would not be compromised even if they were law-abiding citizens. But if Jones shakes Smith's hand, rather than guns him down, there will be no murder. So the integrity (as I called it) of the murder as an individual is a function of individuals distinct from it.

If I say 'The murder was cold-blooded', with 'the murder' as a singular designator for a particular, I am representing a mode in a style appropriate to a concrete particular or substance. To enunciate the truth conditions of "The murder was cold-blooded' in a structurally identical fashion with those of 'The plane was hijacked' would mistakenly convey the impression, to a speaker who knows what 'plane' means but not what 'murder' means, that the truth of the former, like that of the latter, does not presuppose the satisfaction of a series of conditions telescoped into the subject phrase.

It is reasonable to say then that 'The murder was coldblooded' is not a perspicuous form. An abstraction is represented, in a potentially misleading fashion, as concrete. Leibniz gives a parallel example. Rather than say 'The warmth of the water was doubled', we should say 'The water was made twice as hot'. He explains that 'this duplication 
of heat can [thus] be expressed in concrete terms' (Preface to an Edition of Nizolius/126).

8. The link between abstraction and (objectionable) relationality* now yields easily to explication. To operate with abstractions, in the sense unacceptable to Leibniz, is to perpetrate the fiction that they are non-abstract. It is, in effect, to represent abstractions or modes as independent, concrete, individuals.

Why should Leibniz describe the fiction here by speaking of relationality $\left({ }^{*}\right)$ ? Why, that is, should he say that propositions which mistakenly represent abstractions as nonabstract are relational $(*)$ ? There are two internally connected reasons.

First, to treat an abstraction as an independent item, i.e. to treat an abstraction as independent of the item which discharges its abstractness, is to treat the two as if they are genuinely related to each other. But the colour of a table, unlike the vase perched on it, is not independent of the table, and is not genuinely related to it. The vase, for example, can be moved. One cannot transfer the table's colour to another object. We would thus say that there is a pseudo-relation between the colour of a table and the table, by contrast with the genuine relation between the table and the vase.

Now this gives a perfect sense to the claim that overcoming relationality* involves eliminating relationality. Inasmuch as normal cognition does not involve basic substantial items as direct accusatives of experience, it follows that standard relations, as I stated above in section 5, are infected by relationality*. For they hold between non-basic accusatives. So standard relations will be eliminated as the transition is effected to the basic level. But this obviously doesn't mean that relations are eliminated simpliciter.

The second reason for speaking here of relationality* is brought out by Leibniz's claim, encountered already, that items which are 'imaginary' are 'relative to our perceptions'.

In order to tear an abstraction free from the item on which 
it depends - to treat it as an independent individual- the cognising subject must make a substantive intervention with the way things (really) are: an abstraction does not individuate itself.

If, for instance, I represent a mode, such as a table's colour, as an independent individual, i.e. by means of the singular phrase 'this red', my own (perceptual) position is being exploited as an essential lever for prying it free. I focus on, or attend selectively to, the colour, ignoring the object which it qualifies. The colour, again, does not individuate itself. If it is individuated, as in this case, otherwise than by prior reference to the object it modifies, this is essentially accomplished 'relative to my perception'.

Mutatis mutandis, this is roughly what Leibniz means when he says that space is a 'mode of my consideration'. Its status in standard cognition (one can think here of the conception of space as a large vessel or container) is not fully explicable except in terms of the leverage of cognitive intervention, and hence in terms of relationality*. Thus, Leibniz describes phenomenal concepts as concepts which 'thought supports, but which nature does not know in their bare form'?

What occurs when relationality* is surpassed? Consider the sample proposition 'The murder of Smith by Jones was cold-blooded', with 'murder' as a common noun, taking articular complementation, and hence available for standard singular operation. Reformulating, we reach 'Jones murdered Smith cold-bloodedly', or some such. Here, 'murder' reappears verbally, and as so functioning cannot be put to singular use. Mutatis mutandis, Leibniz's identification of relationality* as endemic to standard cognition calls for the reformulation of standard factual propositions. While Leibniz's programme goes far beyond anything which might be

7 I explain the second relational * feature rather intellectualistically, as does Leibniz, in terms of what the cogniser does. But the claim is not at base genetic or historical. Language codifies abstractiona and the cogniser thus inherits resources of representation infected by relationality* as he learns a language. 
undertaken by an analytic philosopher in the name of disclosing deep logical structure, the idea of the move is, as I said, formally less mysterious than Bennett makes out.

9. Given that relationality*, according to Leibniz, is utterly pervasive in standard patterns of thought and talk, it cannot be said that, having reformulated the spatial claim 'The distance between A and B is double that between B and C' as ' $A$ is twice as far from $B$ as $B$ is from $C$ ', along the lines of the reformulation of the murder case above, we have reached metaphysical bedrock. For the fundaments of the relation in the preferred form are spatial items, i.e. nonbasic individuals. So the character of the relation is itself infected by relationality*.

Leibniz states the formal point here exactly: 'modes can be repeated ..., so there can be qualities of qualities' (Preface to an Edition of Nizolius/126). Thus, just as for Spinoza the colour of a table is a mode of a mode, so for Leibniz spatial relations between spatial occupants are modes of modes. Accordingly, further steps must be taken to reach the basic level.

As I have already stressed (see section 5, paragraphs 5-8, and section 8, paragraph 4) we encounter here one of the main roots of the mistaken interpretation of Leibniz's attack on relational* propositions as an attack on $n>1$-place propositions. Normal relations, inasmuch as they hold between non-basic items, are implicated in relationality*. So they must be eliminated in the name of adequate, non-relational*, cognition. But even if all normal relations give way, this does not mean that basic propositions are non-relational. It only means that the relations basic propositions express will differ from anything we are familiar with.

To close the discussion, I want to exploit a striking and systematic parallelism between Leibniz's position and the position of Wittgenstein's Tractatus in order to cash the contents of these last claims.

The Tractatus is in many respects reminiscent of Leib. 
nizean metaphysics, e.g. in the claim that basic items, 'objects', are 'unalterable and subsistent' (2.0271), and that 'if a thing can occur in a state of affairs, the possibility of the state of affairs must be written into the thing itself' (2.012). The first claim echoes Leibniz's dissatisfaction with standard objects for service as basic substances, and the second echoes his thesis that facts about monads can be 'read off' their concepts.

An even more striking parallel concerns Leibniz's denial that relationality* can be permitted. This, we saw, implies that singular modal designators must be superseded. Leibniz offers the following argument:

modes can be repeated to infinity... If all these were things, not only infinity, but also contradiction would result ... [T] he thing would be the form of itself, or a part of its own concept, which implies a contradiction (Preface to an Edition of Nizolius/126).

This corresponds remarkably to Wittgenstein's pivotal claim, in demonstrating the need for objects, that

If the world had no substance, then whether a proposition had sense would depend on whether another proposition was true (2.0211).

To explain Wittgenstein's meaning, we can work with the proposition 'The murder was cold-blooded'. The subject phrase here is a modal designator: it designates a dependent particular. Now a singular subject-predicate proposition has a truth value (Wittgenstein identifies 'sense' with 'truth value' at 2.0212) only if its subject term successfully refers. If the stated proposition has a truth value, then the subject term refers. But as its referent is a dependency, some further proposition, e.g. 'Jones shot Smith', must be true. For the dependency of the referent must be discharged. Now if the singular designators 'Jones' and 'Smith' in turn designate 
dependent particulars, then just as a proposition like 'Jones shot Smith' must be true as a condition of the original statement's having a truth value, so further propositions would have to be true as a condition of 'Jones' and 'Smith' referring successfully, i.e. as a condition of the second proposition's having a truth value. If all singular terms were modal, it would thus be impossible to specify the conditions for a standard referential proposition to have a truth value. So, relying no doubt on the simple fact that we can state truth conditions, and evaluate propositions for truth or falsity, Wittgenstein concludes that there is a rock-bottom level of singular terms - 'names' he calls them- which designate non-abstract individuals or substances.

Leibniz's argument is a variation on the same theme. First appearances notwithstanding, he does not accept the regress Wittgenstein struggles to reject. He says, again, that 'modes can be repeated to infinity'. But, as in the case of his admission that spatial items can be divided without end, which is accepted subject to the background assumption that there are more basic items of a non-spatial kind which are not divisible, so the regress of modes is premissed on the availability, at a deeper level, of non-modes.

Leibniz's point is this. Suppose we have a mode of a mode of a mode of ... The abstractness of the items in the chain must, ex hypothesi, be discharged at some point. Suppose it is claimed that this can be done without leaving the modal chain. If so, we end up with some member of the chain which discharges its own dependency. This is a contradiction in terms - a metaphysical analogue of Baron Munchausen extracting himself from the mud by pulling his own hair.

Given this similarity between Leibniz's claim that relationality* must be overcome and Wittgenstein's denial that all designators can be abstract, we are invited to examine Tractarian views of space as a way of shedding light on Leibniz's stand. For Wittgenstein, like Leibniz, rejects spatial relations at the most basic level.

According to Wittgenstein, 'Space, time, and colour... 
are forms of objects' (2.0251). He also says that 'if is only by means of propositions that material properties are represented - only by the configuration of objects that they are produced' (2.0231). In a manner of speaking, Tractarian 'objects are colourless' (2.0232). So colour is a material property. It is then by the combination of objects that colour is produced. By 2.0251, spatial and temporal properties are also material. As spatial and temporal properties therefore: result from combinations of objects, these combinations must themselves be non-spatial and non-temporal.

At the basic Tractarian level, as at the ground level of Leibnizean analysis, there are no standard ('phenomenal') relations. So both Wittgenstein and Leibniz can be said to demand the ultimate reduction of all standard relations. But far from being unrelated among themselves, it is of course of the very essence of Tractarian objects to be interrelated. This is the very opposite of the conventional view of Leibniz. But surely we must now be sceptical about denying that, in Leibniz's claim that

There is no term so absolute or detached as not to include relations, and the perfect analysis of which does not lead to other things and even to all others (New Essays, 2.25.10),

we do have a genuine anticipation of Wittgentein's statement that

If all objects are given, then at the same time all possible states of affairs are also given (2.0124). ${ }^{8}$

8 Grant $\$ 56436$, from the Faculty of Humanities and Social Sciences, BenGurion University of the Negev, covered part of the material costs of prepar. ing this piece. 
La interpretación que da Russell de la teoría leibniziana de la forma proposicional básica es el punto de vista comúnmente aceptado. Según ella, cada proposición se reduce, a fin de cuentas, a una que atribuye un predicado a un sujeto. La violenta reacción de Jonathan Bennett contra la opinión disidente y razonable de Hide Ishiguro, muestra hasta qué punto la interpretación de Russell se ha enraizado. A pesar de que el punto de vista de $\mathrm{H}$. Ishiguro es interesante y digno de consideración, M. Glouberman no lo acepta.

Un rasgo notable de esta polémica es que los mismos textos que generalmente se aducen en favor de la interpretación de Russell, sean usados por Hide Ishiguro como testimonio en contra. Esto sugiere que, como Glouberman intentará justificar, ninguna interpretación se basa en un entendimiento correcto de las tesis de Leibniz. Para Glouberman, si bien es cierto que de alguna manera Leibniz exige que la relacionalidad se elimine de las proposiciones fácticas estándar como un requisito para que sean metafísicamente aceptables, no es cierto que "relacionalidad" signifique lo que tanto Bennett como Ishiguro creen que significa. En suma, tan pronto como se determina correctamente lo que subyace en el pensamiento de Leibniz, el problema que se discute bajo el rótulo de "Ia teoría de Leibniz de la relacionalidad" aparece bajo una luz completamente distinta.

[Sebastián Lamoyi] 